Volume 8, No.5, September - October 2019

International Journal of Advanced Trends in Computer Science and Engineering

Available Online at http://www.warse.org/IJATCSE/static/pdf/file/ijatcse119852019.pdf

https://doi.org/10.30534/ijatcse/2019/119852019

\title{
Resource Provisioning for various network applications in adhoc networks
}

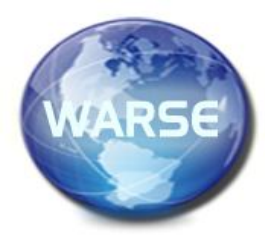

ABSTRACT

Adhoc networks are class of decentralized networks which will not depend on existing infrastructure. Vehicular adhoc networks are only mobile adhoc networks but high speed nodes. There are various network applications which have different resource requirements which will be catered by resources available with the networks. This research study gives an overview of classification of traffic types, resource requirements of different applications and efficiency of different routing protocols in Mobile adhoc networks and Vehicular adhoc networks over one another. MANETs are important communication infrastructure now a days. Because of adhoc networks, frequent disconnections are there, an analysis of quality of service metrics like packet delivery ratio, throughput and error rate has been done in this study.

Key words: MANETs, VANETs, FANETs, AODV, DSR, DYMO

\section{INTRODUCTION}

Broadly, Internet traffic is of two types namely real time and non real time. Real time streaming is further of two types, one is rigid and intolerant applications and the other tolerant and adaptive applications. Real time applications have very stringent QoS (Quality of Service) constraints such as real time audio/video applications as there is strong sensitivity of the human sound perceptions and can become tolerant to QoS interruptions by means of adaptation whereas adaptive applications are capable of adjusting their playback point according to the observed network QoS. Quality of service can always be improved by keenly observing metrics like delay, jitter, bandwidth etc. The QoS properties of network is more dependent on the link layer properties. There are different protocols which work effectively under different scenarios of adhoc networks. Resources can be provided in adhoc networks keeping in view the view the quality of service constraints. The requirements for various network applications have to be gathered first in order to cater the needs of different applications in terms of bandwidth, jitter etc.

\section{LITERATURE REVIEW}

The literature is being studied in detail with respect to network requirements of various applications like video streaming, voice streaming applications and text applications. One of the authors Y chen [1] in his research papers has studied requirements of resource for different network application. Similar study has also been done by T.K Wok [2]. QoS parameters which are important for deciding the quality of service of individual connections or data flows are delay, Jitter, bandwidth and reliability.

There are different routing protocols available which enhance QoS. They are referred as QoS aware protocols. The Existing routing protocols are classified and characterized for vehicular adhoc networks and Mobile adhoc networks. Some routing protocols work well for MANETs whereas others work for VANETs and Flying adhoc networks(FANETs)[3]. FANETs fly in the air. In FANETs, node mobility is much higher than MANETs and VANETs. Applications such as audio/video conferencing, web casting requires very stringent and inflexible Quality of service. The resource allocation of QoS guarantees is much more challenging in VANETs, MANETs and FANET than wired networks. QoS is the performance of any service offered by network to the user. Most of the multimedia applications have very strict OS requirements which must be satisfied.

Liu Jincai et al in [5] have done Adhoc On demand Distance vector (AODV) and Dynamic Source Routing (DSR) and inferred that DSR is much better than AODV in lesser node density. 
Fei Xie, A Hua, Wenjing Wang and Yao H Ho[7] have described video streaming over highway vehicular adhoc networks. Authors in [8] of live video streaming have triggered a mechanism to calculate the backward and frontward transmission ranges of vehicles. Although, video streaming requires a buffer, yet by increasing buffer size may not always improve the quality of service of transmitted video.

Mahdi Asefi in [9] proposed a routing framework for real time video transmission over urban multi hop vehicular adhoc networks scenarios. The comparison of performance of the protocol and increment in coverage area through more communication hops has been evaluated.

In [11] many QoS routing strategies attempt to provide a robust route among nodes and ensure quality of service. There are various factors like node velocity, node position, trajectory and distance which determine the route stability. This paper discusses MURU, GvGrid , PBR and DeReQ (Delay and reliability constrained QoS routing algorithm).

The basic operation of PBR is same as reactive protocols. When a node wants to communicate, it sends route request (RREQ) packet with a TTL (time to live) value that specifies the number of hops to search for a gateway. The lifetime of link between $\mathrm{i}$ and $\mathrm{j}$ is predicted as

Life time $_{\text {link }}=\left(R-\left|d_{i j}\right|\right) /\left|v_{i}-v_{j}\right|$

Where $R$ is communication range of WLAN technology, $\left|\mathrm{d}_{\mathrm{ij}}\right|$ absolute distance between nodes $\mathrm{i}$ and $\mathrm{j}$, vi and vj are velocities.

The route lifetime is calculated as the minimum of all its link lifetimes as done by Vinod Namboodri in [12]. Regarding throughput, when nodes connect to internet, the bottleneck link in terms of bandwidth is the WAN link from gateways to the base station.

GvGrid protocol [13] is also very suitable for urban scenarios where vehicles move at slower speeds in dense traffic. It is not clear that whether GvGrid guarantees any particular QoS level in terms of bandwidth or link delay. This can be further entailed for discussion.

In [14] authors have given a multi hop routing protocol called MURU which is able to find robust paths in urban VANETs to achieve high end to end PDR with low overhead. In [15], author presents a intersection based geographical routing protocol (IGRP) which outperforms existing protocols for city environment. It is based on the selection of road intersections through which a packet must pass to reach the gateway to the internet. Author has tried to improve the transmission range Tr.

In [16] author has discussed multiplayer online games which should have minimum delay and jitter. With the help of [17] author determine the upper performance bound for connection duration, PDR, end to end delay and jitter for unicast based typical highway and urban VANET environments. This area needs to have more research. Definitely, Games would have to have hard QoS constraints.

G Lorkmaz et al in [19] discussed urban multi hop broadcast in VANET. Urban Multihop broadcasting (UMB) has improved upon reliability of broadcast by alleviating a hidden terminal problem through an RTS/CTS style handshake and broadcast storms through black burst signals to select a forwarding node that is farthest from the sender using location information.

Gounjun Yan et al [20] proposed routing protocol which improves QoS of VANET in terms of delay, response time and throughput. Considering the DSR and AODV, improvements are done and a protocol named as VOA (VANETs quality Of service by Adaptive protocol)..

Das et al in [21] has given a comparison of protocol, the link level and MAC are not modeled. In a different study [22] the protocol is discussed as the research performed by Broch et al [23] . Although, for different scenarios as it is understandable that random mobility will not be able to model realistic network behaviors. Pradeep Macharala in [24] proposed on demand QoS routing protocol (AODV-D) for delay sensitive applications in MANETs for overcoming shortcomings of present QS-AODV and AODV protocols. It helps in estimating node delay instead of taking a constant value as in the existing QS-AODV[25]. This gives more precision in estimating end to end delay.

One of the research by Anil K Bisht et al in [26] is to calculate the performance for the position based protocols in vehicular network environment. The metrics such as PDR, throughput, end to end delay and routing overhead have been given using ns2. The protocols were tested by differing transmission range and node density. It is found that LAR (location aided routing) [27][28] outperform DREAM ( Distance routing effect algorithm for mobility )[29]. DREAM is a directional, restricted flooding position based routing protocol. [30]. LAR is on demand routing protocol like AODV and DSR with an additional use of positional information to improve the route discovery phase of reactive adhoc routing approaches. Lei Chen et al in [31] proposed embedding QoS into routing and bandwidth estimation through "Hello" messages. There are two different techniques as Hello and Listen .In mobile topology "Hello" is evaluated as per end to end delay and "Listen" performs better in terms of packet delivery ratio.

Bijan Paul et al [32] discussed merits and demerits of various routing protocols. FSR (Fisher eye State 
Routing) [33] reduces significantly the consumed bandwidth as it exchanges partial routing update information with neighbors only.

GPCR( Greedy perimeter Coordinate routing) [34] is a routing protocol which uses greedy algorithms to forward packet based on a path which is already selected, and which has been designed to handle the challenges of city environment.

Connectivity Aware Routing (CAR) [35] is a routing technique which uses AODV .No local maxima problem is there. CAR is deterministic to search the shortest connected path because CAR has more PDR ratio as compared to GPSR.

VADD (Vehicle assisted Data Delivery) [36] is based on the idea of carry and forward approach by using predictable vehicle mobility. VADD in most case is unsuitable for application which are tightly constrained by delay requirements.

Fleetnet [37] gives both internet access and communication among passengers of cars in near by location to play games. A pure V2V cannot address these applications domains and there is a definite need for V2I infrastructure.

One of the author ke zhang [39] has mentioned about cloud based mobile edge computing offloading framework for VANETs. Effectiveness of computation strategies with respect to VANETs and MANETs have been studied.

One of the author F Cunha [40] has discussed various open problems and issues related to vehicular adhoc networks . Various applications like road congestion status, comfortable driving, accident avoidance can be run successfullywith the help of VANETs. Author munish devi [41] has very well explained MANETs and enhanced DSR for IoT scenario as internet of things is quite upcoming field.

Compression techniques are very important in resource provisioning in adhoc networks. These techniques are helpful in managing resources in best possible manner . In a study author[42] has discussed H.264 technique for video compression will be new driving force for digital video especially in adhoc networks.

The extant literature suggests certain findings which will be discussed in next section. Various solutions have been discussed to improve QoS by different

\begin{tabular}{|l|l|l|l|}
\cline { 1 - 2 } Application & \multicolumn{3}{l|}{} \\
\cline { 1 - 2 } $\begin{array}{l}\text { QoS } \\
\text { Metrics }\end{array}$ & $\begin{array}{l}\text { Respons } \\
\text { e Time }\end{array}$ & Delay & Jitter \\
\cline { 1 - 2 } Email & $2-5 \mathrm{~s}$ & Low & N/A \\
\hline Telnet & $<2 \mathrm{~s}$ & $<250 \mathrm{~ms}$ & \\
\hline Broadcastin & $2-5 \mathrm{~s}$ & $<150 \mathrm{~ms}$ & $<100 \mathrm{~m}$ \\
\hline
\end{tabular}

authors. However, few works related to online games, 2D videos, effects of traffic lights on various routing protocols have not been discussed.

\section{ANALYSIS}

The above mentioned literature review leads to certain inferences. MURU multihop routing protocols can be used for Video streaming applications. Some Protocols like Application aware Quality of service (AAQR), Delay sensitive adaptive routing protocol (DSARP) have already been implemented on MANETs and can further be implemented on VANETs. It is being observed that GvGrid routing protocol does not guarantee any particular QoS metric in terms of bandwidth or link delay. AODV shows better performance for most of the applications in highway scenarios in vehicular environment, however DSDV is considered unsuitable for VANETs. There is no comparative study done on MURU and (Delay and reliability constrained QoS algorithm ) DeReq as both are more concerned about reliability and stability of path selected for data transfer.

Some of the solutions have been selected to discuss their suitability for video transmission and compare their performance. Few of the techniques like WAVE (Wireless access in vehicular environment), NCDD (network coding based data dissemination) described in detail in [38] and REACT-DIS (Reactive, Density Aware and Timely Dissemination) protocol to form a reliable cross layer technique as they handle video streaming challenges in different protocol layers, which can offer high delivery ratio, low end to end delay while keeping transmission costs limited. None of the proposed solutions yet discuss solutions which has optimum performance in both urban and highway scenario. Definitely, online games and 2D videos transmission need certain attention. There is less study of impact of traffic signs, traffic lights on the performance of routing protocols.

Some of the findings have been tabulated in Table 1 as mentioned below and which can help us to focus on certain thrust areas.

Table 1: Requirements of applications in terms of QoS Metrics

\begin{tabular}{|l|l|l|l|}
\hline $\mathrm{g}$ & & $\mathrm{s}$ \\
\hline $\begin{array}{l}\text { Video } \\
\text { Broadcastin } \\
\mathrm{g}\end{array}$ & $2-5 \mathrm{~s}$ & $<150 \mathrm{~ms}$ & $\begin{array}{l}<100 \mathrm{~m} \\
\mathrm{~s}\end{array}$ \\
\hline $\begin{array}{l}\text { Audio on } \\
\text { Demand }\end{array}$ & $2-5 \mathrm{~s}$ & $<150 \mathrm{~ms}$ & $\begin{array}{l}<100 \mathrm{~m} \\
\mathrm{~s}\end{array}$ \\
\hline
\end{tabular}




\begin{tabular}{|l|l|l|l|}
\hline $\begin{array}{l}\text { Web } \\
\text { Browsing }\end{array}$ & $2-5 \mathrm{~s}$ & $<400 \mathrm{~ms}$ & \\
\hline FTP & $2-5 \mathrm{~s}$ & Medium & N/A \\
\hline $\begin{array}{l}\text { Video on } \\
\text { Demand }\end{array}$ & & $<150 \mathrm{~ms}$ & \\
\hline $\begin{array}{l}\text { Audio } \\
\text { Conferenci } \\
\text { ng }\end{array}$ & & $<150 \mathrm{~ms}$ & $<400 \mathrm{~m}$ \\
\hline $\begin{array}{l}\text { Video } \\
\text { Conferenci } \\
\text { ng }\end{array}$ & & $<150 \mathrm{~ms}$ & $<400 \mathrm{~m}$ \\
\hline $\begin{array}{l}\text { Videophon } \\
\text { y }\end{array}$ & & $<100 \mathrm{~ms}$ & $<400 \mathrm{~m}$ \\
\hline $\begin{array}{l}\text { VOIP } \\
\text { Audio } \\
\text { Graphics } \\
\text { conferencin } \\
\text { g }\end{array}$ & $<150 \mathrm{~ms}$ & $<150 \mathrm{~ms}$ & $<30 \mathrm{~ms}$ \\
\hline $\begin{array}{l}\text { Ecommerce } \\
\text { Application } \\
\text { s }\end{array}$ & & $<150 \mathrm{~ms}$ & $<400 \mathrm{~m}$ \\
\hline
\end{tabular}

*Missing Values are not available in Literature

Table 2: Comparative Study of the different Routing Protocols based upon the different QoS metrics

\begin{tabular}{|c|c|c|}
\hline $\begin{array}{l}\text { Protoc } \\
\text { ols }\end{array}$ & $\begin{array}{ll}\text { QoS } & \text { Metrics } \\
\text { Studied } & \\
\end{array}$ & Limitations \\
\hline $\begin{array}{l}\text { PBR } \\
\text { AODV }\end{array}$ & $\begin{array}{l}\text { Improves } \\
\text { Lifetime of link, } \\
\text { Increases Route } \\
\text { Length, Dropped } \\
\text { Packets Ratio } \\
\text { Less }\end{array}$ & $\begin{array}{l}\text { Can lead to } \\
\text { smaller } \\
\text { throughput and } \\
\text { higher energy } \\
\text { consumption }\end{array}$ \\
\hline $\begin{array}{l}\text { GVGri } \\
\text { d } \\
\text { GPCR }\end{array}$ & $\begin{array}{l}\text { Maintains a route } \\
\text { with long } \\
\text { lifetime }\end{array}$ & $\begin{array}{l}\text { Does not } \\
\text { guarantee BW or } \\
\text { link Delay }\end{array}$ \\
\hline $\begin{array}{l}\text { MURU } \\
\text { AODV } \\
\text {,DSR, } \\
\text { GPSR }\end{array}$ & 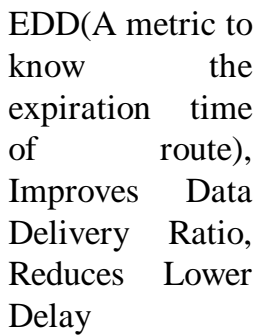 & $\begin{array}{l}\text { Due to rectangular } \\
\text { broadcast areas, } \\
\text { may be susceptible } \\
\text { to local optimums. }\end{array}$ \\
\hline $\begin{array}{l}\text { IGRP, } \\
\text { GPSR, } \\
\text { GPCR }\end{array}$ & $\begin{array}{l}\text { Works on } \\
\text { Transmission } \\
\text { Range, Reduces } \\
\text { Error Rate }\end{array}$ & $\begin{array}{lr}\text { Delay increases } \\
\text { with the increase } \\
\text { in network } \\
\text { density. }\end{array}$ \\
\hline
\end{tabular}

\begin{tabular}{|c|c|c|}
\hline & & $\begin{array}{l}\text { Does not choose } \\
\text { routes which have } \\
\text { very high number } \\
\text { of nodes result in } \\
\text { network } \\
\text { contention }\end{array}$ \\
\hline $\begin{array}{l}\text { VOA, } \\
\text { AODV } \\
\text {,DSR }\end{array}$ & $\begin{array}{l}\text { Improves } \\
\text { Bandwidth, } \\
\text { Reduces Routing } \\
\text { time, Improves } \\
\text { Response Time } \\
\end{array}$ & $\begin{array}{l}\text { Response time } \\
\text { little less when } \\
\text { relative speed is } \\
\text { high }\end{array}$ \\
\hline $\begin{array}{l}\text { QS-A } \\
\text { ODV, } \\
\text { AODV }\end{array}$ & $\begin{array}{lr}\text { More } & \text { Accuracy } \\
\text { in } & \text { estimating } \\
\text { Delay } & \end{array}$ & \\
\hline $\begin{array}{l}\text { FSR, } \\
\text { GSR }\end{array}$ & $\begin{array}{l}\text { Reduces } \\
\text { consumed } \\
\text { Bandwidth, } \\
\text { Improves } \\
\text { Delivery Ratio }\end{array}$ & $\begin{array}{l}\text { Entire topology } \\
\text { exchange, } \\
\text { consumes a } \\
\text { considerable BW }\end{array}$ \\
\hline $\begin{array}{l}\text { DeReQ } \\
\text { AODV }\end{array}$ & $\begin{array}{l}\text { Maximum } \\
\text { Reliability, } \\
\text { Reduces link } \\
\text { Delay }\end{array}$ & $\begin{array}{l}\text { Mainly relies on } \\
\text { vehicles mobility } \\
\text { that is highly } \\
\text { dynamic }\end{array}$ \\
\hline $\begin{array}{l}\text { RBF-H } \\
\text { SBF-H }\end{array}$ & $\begin{array}{l}\text { Reduces packet } \\
\text { delay, reduces } \\
\text { packet loss rate }\end{array}$ & $\begin{array}{l}\text { Packet loss caused } \\
\text { by buffer overflow } \\
\text { which is } \\
\text { unavoidable. }\end{array}$ \\
\hline $\begin{array}{l}\text { CAR } \\
\text { GPSR }\end{array}$ & $\begin{array}{l}\text { Improvement in } \\
\text { PDR, Reduces } \\
\text { Average packet } \\
\text { delays }\end{array}$ & $\begin{array}{l}\text { Path discovery } \\
\text { phase lead to } \\
\text { overhead, cannot } \\
\text { adjust with } \\
\text { different sub paths } \\
\text { when traffic } \\
\text { environment } \\
\text { changes. }\end{array}$ \\
\hline
\end{tabular}


Table 3: Protocols that ensure quality of service along with the ease of handling applications

\begin{tabular}{|l|l|}
\hline Protocol & $\begin{array}{c}\text { Applications easily handled by } \\
\text { Protocol } \\
\text { Real time Data Dissemination in } \\
\text { urban }\end{array}$ \\
\hline PBR & Email, FTP, Telnet \\
\hline GvGrid & Multimedia streaming \\
\hline MURU & Real time data dissemination \\
\hline IGRP & Video streaming \\
\hline VOA & Multimedia Applications \\
\hline QS-AODV & FTP, Email, Telnet \\
\hline VADD & $\begin{array}{c}\text { Multimedia streaming, Real } \\
\text { Time Data Dissemination } \\
\text { DeReq }\end{array}$ \\
\hline RBF & Video Streaming \\
\hline
\end{tabular}

\section{IMPLICATIONS}

The above literature review in tabulated form suggests that there are various VANET applications that have different requirements in terms of QoS metrics or resources which can be provided by different routing protocols. The efficacy of these protocols varies under different scenarios i.e sparse and dense. Table 2 gives us tabulated information as far as various routing protocols are concerned along with QoS metrics studied and scenarios taken into consideration. Table 3 is providing information regarding applications handled by different protocols at ease.The applications like online games, e commerce websites, live video streaming require more secure and hard QoS constraints in terms of delay, jitter and response time as compared to video/audio streaming . Another set of applications like email, FTP, telnet are not bounded by such constraints. Different protocols have been surveyed and they consider different QoS metrics at a time like AODV improves PDR, reduces delay whereas PBR works on link lifetimes, MURU works on expected degree disconnection (EDD), OLSR and GRP work very well for greater network sizes, IGRP specifically works for the cluster of nodes at intersections in urban scenario, VOA improves bandwidth and has been applied to highway scenario now it can be applied to city environment and so on. Attention needs to be drawn towards efficacy of various VANET routing protocols for delay sensitive applications such as 2D video streaming, online games. The authors are working to propose a solution which has optimum performance for most of the applications in both urban and highway scenario in VANETs by developing a hybrid protocol which will be sufficing the requirements for network applications by applying the existing Network Coding technique to improve the quality of service. Focus is to develop a routing protocol which can satisfy resource requirements of most of the video streaming applications. Response time of different applications shall be collected so that improvement can be evaluated in applications. Qualitative comparative data regarding different protocols shall be worked out for two or more applications. We shall vary our Constant Bit Rate and Variable Bit Rate for different video streaming applications while studying their Packet Delivery Ratio, End to End Delay, Error Rate, loss rate and so on. Focus shall be on developing a hybrid protocol for improving QoS in video streaming applications.

\section{CONCLUSION}

There are various routing protocols that will fulfill the requirements of different applications which are running on adhoc networks including mobile adhoc networks, vehicular adhoc networks, flying adhoc networks have been studied. The routing protocols which are associated with applications like multimedia streaming, video streaming, video conferencing, live video streaming have been exhaustively reviewed in this article. The performance of applications can be evaluated in terms of PDR, delay, jitter, bandwidth consumption and response time. Certain hybrid protocols may be designed by combining two features of different routing protocols like estimating bandwidth and improving the bandwidth or saving energy. Different mobility models can be used for simulation of different traffic scenarios so as to study the network applications on VANETs may be done in future. Quality of service metrics have been analyzed with existing routing protocols. The intelligent transport system is strengthened a lot by way of improving quality of service of vehicular adhoc networks.

\section{REFERENCES}

[1] Yan Chen, Tony Farley, Nong Ye “ QOS Requirements of network applications on internet" Information . Knowledge . System Management. IOS press 2004 pp 55-76.

[2] Residential Broadband Internet Services and Application Requirements" $\mathrm{T}$ K Wok IEEE Communications Magazine June 1997.

[3] www.ciscopress.com/articles.

[4] Jerome Haerri, Fethi Filali , Christian Bonnet “ Performance comparison of AODV and OLSR in VANETs urban environment under Realistic mobility Patterns" Conference June 2006. 
[5] Liu Jianci, Chen Feng, Xu Jiskai " The study of routing strategies in vehicular adhoc networks" IEEE Explore 2010. https://doi.org/10.1109/WCSP.2010.5633461

[6] Xiong Wei, li Qing "Performance evaluation of data dissemination for vehicular adhoc networks in highway scenarios" International archives of Photgrammetery 2002

[7] Fei Xie, Kien A Hua Wang and Yao H Ho “ Performance study of live video streaming over highway vehicular adhoc networks." in Proceedings of VTC- 1st IEEE International Symposium on Wireless Vehicular Communications (WiVeC), pp. 2121 - 2125, Baltimore, MD, Sept. 30 - October 1, 2007.

[8] M Rocetti, M Gerla , C E Palazzi and G Pau “ First Responders 'Crystal Ball: How to scry the Emergency from a remote vehicle in proceedings of IPCCC 2007/IEEE international workshop on Research Challenges in Next Generation Networks for first responders and critical infrastructures LA Apr 2007

[9] Mahdi Asefi, Jon W Mark and Xumein ( Sherman) “ An application centric inter vehicle routing protocol for video streaming over Multi Hop urban VANETs" IEEE communications society. IEEE ICC 2011 proceedings https://doi.org/10.1109/icc.2011.5962635

[10] Abdullah Jamali, N Naja " Comparative analysis of adhoc networks routing protocls for multimedia streaming” IEEE Explore 2009 ICMCS '09.

[11] James Bernsen, D Manivannan "Routing Protocols for vehicular adhoc networks that ensure Quality of service" IEEE Explore Fourth international conference on wireless and mobile communications 2008.

[12] Vinod Namboodri , L Gao IEEE Transactions 2007 “ Prediction based routing Protocol for vehicular adhoc networks

[13] W Sun, H Yamaguchi, K Yuki masa IEEE Explore 2006 " GvGrid A QOS routing protocol for vehicular adhoc networks"

[14] Z Ho, H Zhu, Kia Hakki, K Makki, N Pissinou “ Multi hop routing protocol for urban vehicular adhoc networks" IEEE Explore 2006 Third international conference system networks n services, 2006

[15] H Saleet, R Langar, K Naik, R Boutaba IEEE Explore 2011 " Intersection based geographical routing protocols for VANETS: A proposal and analysis" https://doi.org/10.1109/TVT.2011.2173510

[16] O K Tonguz, M Boban adhoc networks 2010 Elseveir " Multiplayer Games over vehicular adhoc networks : A new Application".

[17] M Boban, Geoff Miesk, o k Tonguz "What is the best achievable QoS for unicast Routing in VANET?" IEEE 2008.
[18] Akhtar Hussain et al "Performance Comparison of Topology and Position Based Routing Protocols in Vehicular Network Environments" International Journal of Wireless \& Mobile Networks( IJWMN) Vol 3 no 4, Aug 2011.

[19] G Korkmaz, E Ekici , F Ozguner, U Ozguner Proceeding of $1^{\text {st }}$ ACM 2004" Urban multi hop broadcast protocol for inter vehicle communication system" https://doi.org/10.1145/1023875.1023887

[20] G Yan, B Rawat," Provisioning vehicular adhoc networks with QoS" IEEE computer society 2010.

[21] S R Das et al "Comparative Performance Evaluation of Routing Protocols for Mobile Adhoc Networks" In $7^{\text {th }}$ Int Conf on Comp Comm. And Networks pp 153-161 Lafayette LA Oct 1998.

[22]P Johnson et al “ Scenario Based Performance Analysis of Routing Protocols for Mobile Adhoc networks" In Proc IEEE/ACM Mobicom'99. Pp 195-206 Seattle WA, Aug 1999.

[23] J Broch et al " A performance comparison of Multi Hop Wireless Adhoc Network Routing Protocols" In Proc ACM MOBICOM.

[24]P Macharala "QoS routing for delay sensitive applications" IEEE Explore 2008.

[25]C E Perkins, Royar, Das S“ Quality of service for adhoc on demand routing vector Routing" IETF Draft draftietf manet aodv-05.txt(2000b)

[26] A Bisht, B Kumar " Simulation based analysis of position based routing protocols " International journal of advances in computer networks and security

[27] Young-Bae Ko, Nitin H Vaidya " Location aided routing in mobile adhoc networks," ACM journal of Wireless Networks, Vol 6 no 4 pp 307-321, July 2000.

[28] T camp, J Boleng, B Williams, L Wilcox and W Navidi, "Performance comparison of two Location based routing Protocols for Adhoc Networks", Proceedings of the IEEE INFOCOM, Vol 3 , pp 1678-1687, 23-27 June, 2002.

[29] S.Basagani et al," A Distance routing effect Algorithm for Mobility (DREAM), Proc 4 th Annual ACM/IEEE Int. Conf. Mobile computing and Networking, MOBICOM '98, Dallas, TX, USA 1998 pp 76-84

[30] Miguel Gracia de la Fuente, Houda Labiod Performance Analysis of position based routing Approaches in VANETs", Proceedings of $9^{\text {th }}$ International Conference on mobile and wireless Communication Networks, Cork Ireland Sept 19-21, 2007.

https://doi.org/10.1109/ICMWCN.2007.4668172

[31] Lei Chen, Wendi B," QoS-Aware Routing based on Bandwidth Estimation for Mobile Adhoc Networks “ IEEE Journal on selected Areas in Communication. Vol 23, No 3, March 2005. 
[32] B Paul et al "Vanet Routing Protocols : Pros and Cons" International Journal of Computer Applications" Vol 20 No 3 Apr 2012

[33] Pei, G., Gerla, M and Chen, T-W(2000), "Fish Eye State Routing: A Routing Scheme for Adhoc Wireless Networks" Proc ICC 2000, New Orleans, LA, June 2000.

[34] Lochert C, Mauve,M., F' ussler, H and Hartenstein , H, "Geographic Routing in City Scenarios," SIGMOBILE Mob Comput, Commun Rev Vol 0 no 1 pp 69-72 2005.

[35] Naumov, V., Gross T.R (2007), "Connectivity-Aware Routing(CAR) in Vehicular Adhoc Networks". INFOCOM 2007. $26^{\text {th }}$ IEEE International Conference on Computer Communications. IEEE, Vol, no pp. 1919-1927, 6-12 May, 2007.

[36] Zhao,J., Cao(2006), "Vehicle -Assisted Data Delivery in Vehicular Adhoc Networks" INFOCOM

[37] W Enkelmann "Fleetnet - Applications for Inter Vehicle Communications" IEEE Explore 2003.

[38] J S Park, U Lee, Sy Oh, M Gerla D S lun "Emergency related video streaming using network coding" VANET '06 ACM New York

[39] K Zhang et al "Mobile edge computing for vehicular adhoc networks: A promising networks paradigms for predictive off loaing",IEEE explore 2017

[40] Filpie Cunha " Data communication in VANETs: A survey, applications and challenges" Adhoc networks, Elseveir 2016.

https://doi.org/10.1016/j.adhoc.2016.02.017

[41] Munisha devi, nasib singh gill," Performance evaluation of Dynamic source routing in smart environment" Int journal of advanced trends in computer science and engineering" IJATCSE Vol. 8 no 2 Mar 2019

[42] Shahin Sheikh, Manjusha Deshmukh “ video compression using H.264: A review" Int. journal of advanced trends in computer science and engineering" IJATCSE Vol 2 No 1 pages 52-54
2006. 25 th IEEE International Conference on Computer Communications. Proceedings, Vol no pp 1-12, April 2006. 